\title{
ANALYZING THE CONTRIBUTION OF THE DENTAL COMPONENTS AND ABNORMAL HABITS IN THE DEVELOPMENT OF DENTAL OPEN BITE IN GROWING CHILDREN: A CROSS SECTIONAL STUDY
}

\author{
Mostafa M. El-Dawlatly* and Mai H. Aboulfotouh*
}

\begin{abstract}
Dental Open bite malocclusion could be caused by either aberrant dental development or abnormal oral habits.

Aim: The current study aimed at analyzing the causative factors of dental open bite in a group of growing female subjects having normal vertical growth pattern.

Materials and methods: Dental measurements were performed on lateral cephalometric radiographs and study models of 176 growing females with an age range of 9-12 years and average vertical skeletal growth pattern. They were divided into 2 equal groups; group 1 consisted of subjects with dental open bite and group 2 consisted of subjects with normal overbite. The existence of oral habits was also recorded for each patient in the 2 groups.
\end{abstract}

Results: The flattened curve of Spee and the proclination of the upper incisors were statistically higher in the open bite group. The ratios of occurrence of thumb sucking, tongue thrusting and mouth breathing habits in the open bite group were statistically higher than in the control group.

Conclusions: The flattened curve of Spee, and the proclination of upper incisors, together with some oral habits should be cautiously addressed by the orthodontic clinician during the treatment planning process of open bite malocclusions. This could help in resolving the causative factor of the malocclusion.

KEYWORDS: Dental open bites, Oral habits, Nnegative overbite, Dental components, Curve of Spee

* Lecturer, Department of Orthodontics, Faculty of Dentistry, Cairo University. Morth, RCSED 


\section{INTRODUCTION}

Dental open bite malocclusion is characterized by lack of contact between the upper and lower incisors usually with the lack of an increased vertical growth pattern. The prevalence of anterior open bite varies within the range of $1.5 \%$ to $11 \%$ and differs between groups with diverse ethnicity, chronological and dental ages ${ }^{1}$. It was claimd that approximately $3.5 \%$ of patients with an age range of eight to seventeen years had anterior open bites ${ }^{2}$. The treatment used in anterior open bite therapy should not be the only apprehension of the orthodontists. The orthodontist should address this malocclusion, via a thorough focus on the etiologic factors that contribute to a cause-based treatment plan. The etiology of dental open bite includes a number of muscular imbalances and abnormal oral habits, yet an established open bite malocclusion overlies environmental and dental inconsistencies ${ }^{3}$.

Some recent studies that dealt with the open bite problems concentrated on the diverse treatment techniques mainly concerning skeletal anchorage use in the intrusion of posterior teeth ${ }^{4,5}$. The focus on mini-implant supported intrusion had been increasing relying on its effectiveness and the reduced risk of post-operative relapse $e^{6,7,8}$. Meanwhile, studies investigating the components of the malocclusion have been abandoned.

Certain studies compared the dento-alveolar features of open bite between different ethnic groups ${ }^{9}$ where 51 black subjects with open bites were compared to 52 subjects with normal anterior overbite to find cephalometric differences in between. In another study by Arat et al..$^{12}$, the etiology behind the development of open bite was investigated. Seventy seven anterior open-bite patients were examined and divided into three different groups; functional, skeletal or a combination of both. It was found that most of the hyper-divergent cases, had a functional etiologic background in terms of an abnormal habit or neuromuscular disease. Moreover, subjects having Angle Class III and Class II malocclusions were divided into two groups, one group had anterior open bite, while the other group had a normal anterior overbite. The open bite patients were found to have discrepancies in the maxillary and mandibular skeletal pattern. Thus, the ideal way for treating an open bite case should be accomplished through addressing the main causative factors ${ }^{10,11}$.

The orthodontic literature does not have enough data in terms of analyzing the underlying dental and functional etiologic factors that contributed to the development of dental open bite malocclusion. The current study aimed at exploring the different dental components and habits that may cause anterior open bites in children with normal vertical growth patterns and to compare them to a matched normal overbite group.

\section{MATERIALS AND METHODS}

Pre-treatment lateral cephalograms and study models of 176 female patients with age ranging from 9-12 years were collected. The sample was divided into 2 equal groups of 88 subjects each, one possessing dental open bite and the other was a matched control group with normal overbite. Those patients were carefully chosen from about 3780 patients' records at the Outpatient Orthodontic Clinic in the Faculty of Dentistry, Cairo University. All of the included patients fulfilled the following criteria:

1. They had no history of a previous orthodontic treatment.

2. The lack of craniofacial disorders.

3. All teeth were present

4. They had normal vertical skeletal growth pattern

In order to extract the required data regarding the abnormal oral habits for the selected patients, the patients' files were used. The habits included thumb sucking, mouth breathing and tongue thrusting.

The dental measurements were driven from the lateral cephalometric radiographs and study models. Description of the measurements used in the 
study were shown in table (1) and figures (1,2\&3). Measurements were done three times; two of them were accomplished by the same observer (main investigator) and the third time was done by another observer.

\section{Statistical analysis}

Statistical analysis was performed with SPSS $16{ }^{\circledR}$ (Statistical Package for Scientific Studies), Graph pad prism \& windows excel.

1. Reliability analysis for inter observer and intra

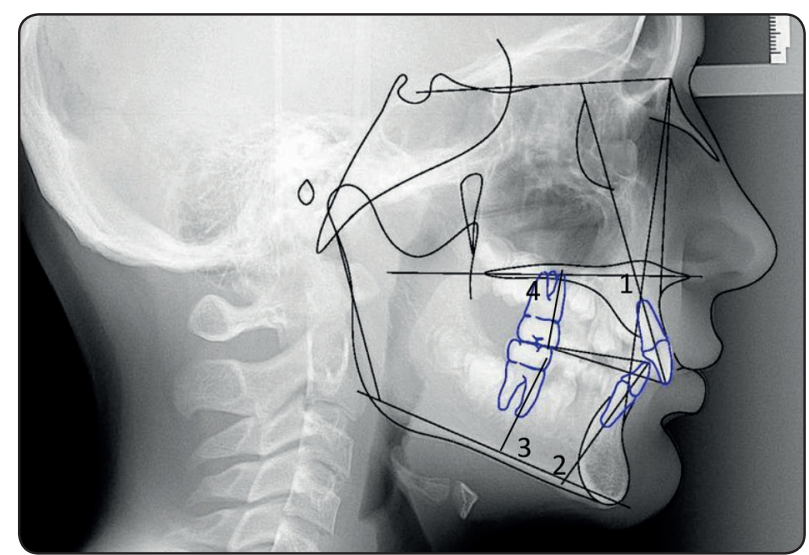

Fig. (1) lateral cephalometric radiograph showing dental measurements 1: $\mathrm{u} 1$ angulation to palatal plane, 2: $\mathrm{L} 1$ angulation to mandibular plane, 3: U6 angulation to palatal plane, 4: L6 angulation to mandibular plane. observer measurements were carried out using Dahlberg error (DE) and relative Dahlberg error (RDE) as well as Concordance Correlation Coefficient (CCC).

2. Paired t-test was used to spot the significance of the difference between the mean of each component in the open bite and normal overbite groups and the significance level was set at $\mathrm{P} \leq 0.05$.

3. Chi-square test was used to measure the significance of the difference of the ratio of occurrence of oral habits between the 2 groups.

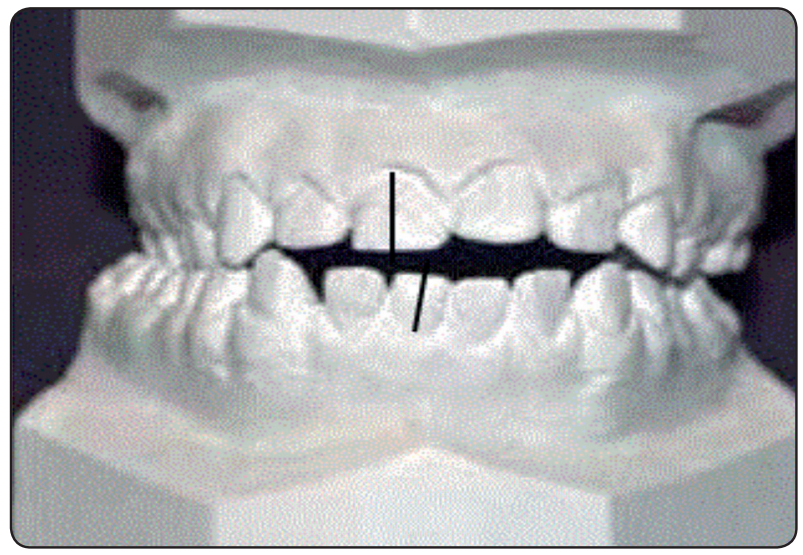

Fig. (2) Study model measurements showing upper and lower central incisors' crown heights.

TABLE (1) Description of the dental measurements used on lateral cephalograms and study models

\begin{tabular}{|l|l|l|}
\hline \multicolumn{1}{|c|}{ Measurement } & \multicolumn{1}{|c|}{ Source } & \multicolumn{1}{c|}{ Description } \\
\hline L6 Angulation & Ceph & $\begin{array}{l}\text { Angulation of the lower 1 } 1^{\text {st }} \text { molar as measured between the long axis of the lower } \\
1^{\text {st }} \text { molar and the mandibular plane(anterior angle) }\end{array}$ \\
\hline U6 Angulation & Ceph & $\begin{array}{l}\text { Angulation of the upper } 1^{\text {st }} \text { molar as measured between the long axis of the upper } \\
1^{\text {st }} \text { molar and the maxillary plane(posterior angel) }\end{array}$ \\
\hline U1- PP angle & Ceph & $\begin{array}{l}\text { Angulation of the upper incisor as measured between the long axis of the upper } \\
\text { incisor and the maxillary plane }\end{array}$ \\
\hline L1- MP angle & Ceph & $\begin{array}{l}\text { Angulation of the lower incisor as measured between the long axis of the lower } \\
\text { incisor and the mandibular plane }\end{array}$ \\
\hline L1 crown height & Study model & $\begin{array}{l}\text { Height of the upper central incisors as measured from a line extending between } \\
\text { the mid-point of the cervical margin and the mid-point of the incisal edge }\end{array}$ \\
\hline Curve of Spee & Study model & $\begin{array}{l}\text { Height of the lower central incisors as measured from a line extending between } \\
\text { the mid-point of the cervical margin and the mid-point of the incisal edge }\end{array}$ \\
\hline
\end{tabular}




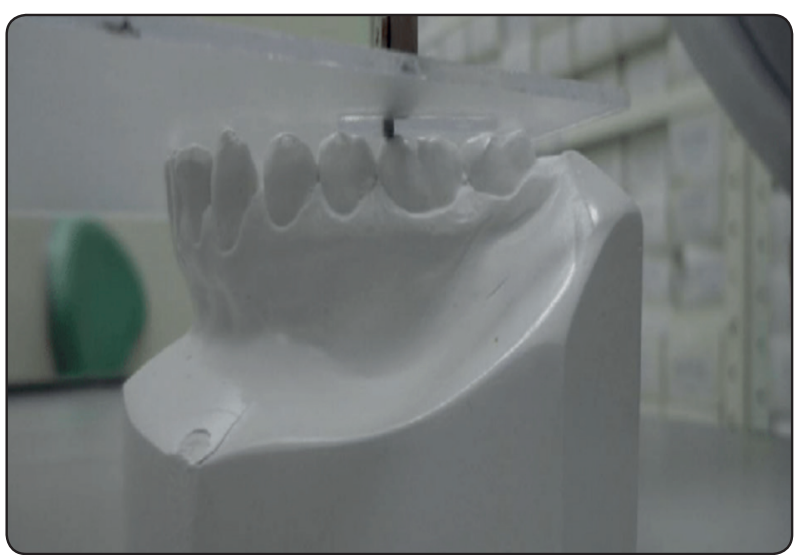

Fig. (3) Measurement of the curve of Spee on study model

\section{RESULTS}

The results were driven as follows:

1. Results showed excellent inter-observer and intra-observer reliability as RDE did not exceed $10 \%$ and CCC values were recorded between 0.991 and 1 .
2. Hypothesis t-test was undergone and detected the following:

a) Statistically significant difference in the mean of the upper incisors' proclination $\left(\mathrm{P}=0.001^{* *}\right)$, where the open bite group showed more U1 proclination than the normal overbite group (table 2).

b) Highly statistically significant difference in the depth of the curve of Spee between the 2 groups, where the group having anterior open bite showed a shallower curve of Spee than the normal overbite group (table 2)

c) All other dental parameters did not show statistical significance between the 2 groups.

3. Chi square test detected a statistically higher ratio of occurrence of thumb sucking, tongue thrusting and mouth breathing habits in the open bite group as shown in table (3).

TABLE (2) Significance of contributions of the dental components to open bite malocclusion with the hypothesis t-test.

\begin{tabular}{|c|c|c|c|c|c|c|}
\hline \multirow{2}{*}{ Measurement } & \multirow[b]{2}{*}{ Groups } & \multirow[b]{2}{*}{ Mean } & \multirow[b]{2}{*}{ SD } & \multicolumn{2}{|c|}{ Paired Differences } & \multirow[b]{2}{*}{ P value } \\
\hline & & & & Mean & SD & \\
\hline \multirow{2}{*}{ L6 Angulation } & Normal & $80.77^{\circ}$ & 4.18 & \multirow{2}{*}{$-1.60^{\circ}$} & \multirow{2}{*}{6.20} & \multirow{2}{*}{0.24949} \\
\hline & Open B & $82.37^{\circ}$ & 4.02 & & & \\
\hline \multirow{2}{*}{ U6 Angulation } & Normal & $83.33^{\circ}$ & 3.98 & \multirow{2}{*}{$0.08^{\circ}$} & \multirow{2}{*}{4.67} & \multirow{2}{*}{0.93596} \\
\hline & Open B & $83.25^{\circ}$ & 3.91 & & & \\
\hline \multirow{2}{*}{ U 1 crown height } & Normal & $11.09 \mathrm{~mm}$ & 3.69 & \multirow{2}{*}{$-0.66 \mathrm{~mm}$} & \multirow{2}{*}{5.57} & \multirow{2}{*}{0.59473} \\
\hline & Open B & $11.74 \mathrm{~mm}$ & 3.85 & & & \\
\hline \multirow{2}{*}{ L1 crown height } & Normal & $10.88 \mathrm{~mm}$ & 3.71 & \multirow{2}{*}{$-0.56 \mathrm{~mm}$} & \multirow{2}{*}{5.29} & \multirow{2}{*}{0.63567} \\
\hline & Open B & $11.44 \mathrm{~mm}$ & 3.61 & & & \\
\hline \multirow{2}{*}{ U1- PP angle } & Normal & $103.98^{\circ}$ & 5.49 & \multirow{2}{*}{$2.82^{\circ}$} & \multirow{2}{*}{1.33} & \multirow{2}{*}{$0.001^{* *}$} \\
\hline & Open B & $106 . .79^{\circ}$ & 6.8 & & & \\
\hline \multirow{2}{*}{ L1- MP angle } & Normal & $99.61^{\circ}$ & 4.63 & \multirow{2}{*}{$-0.96 \mathrm{~mm}$} & \multirow{2}{*}{6.58} & \multirow{2}{*}{0.50981} \\
\hline & Open B & $100.58^{\circ}$ & 4.82 & & & \\
\hline \multirow{2}{*}{ Curve of Spee } & Normal & $3.87 \mathrm{~mm}$ & 1.80 & \multirow{2}{*}{$2.34 \mathrm{~mm}$} & \multirow{2}{*}{2.16} & \multirow{2}{*}{$0.0000^{* * *}$} \\
\hline & Open B & $1.53 \mathrm{~mm}$ & 0.94 & & & \\
\hline
\end{tabular}

** $P \leq 0.001 \quad * * * P \leq 0.0001$ 
TABLE (3) Significance of contributions of the oral habits to open bite malocclusion using the chi-square test.

\begin{tabular}{|l|c|c|c|c|}
\hline \multicolumn{1}{|c|}{ Abnormal Habit } & Normal Group & Open Bite Group & Chi-Square & P-value \\
\hline Mouth breathing & $36 \%$ & $56 \%$ & 4.34 & $0.037^{*}$ \\
\hline Tongue thrusting & $31 \%$ & $68 \%$ & 13.82 & $0.002^{* *}$ \\
\hline Thumb sucking & $20 \%$ & $64 \%$ & 23.04 & $0.000^{* * *}$ \\
\hline
\end{tabular}

$* P \leq 0.05$

$* * P \leq 0.001$

$* * * P \leq 0.0001$

\section{DISCUSSION}

Being one of the most challenging malocclusions in an orthodontic clinician's daily practice, open bite is defined as a lack of vertical overlap between the upper and lower incisors. The etiology of anterior open bites was proven to be caused by more than one factor. A dental open bite is usually referred to the circumscribed anterior open bite that is commonly caused by an abnormal habit or an aberrant dental development. Patients having pure dental open bite usually present with normal to low mandibular plane angles ${ }^{3}$.

Studies analyzing open bite components have stressed on comparing the characteristics of an open bite group with a control group with normal overbites. Ellis, McNamara and Lawrence ${ }^{10}$ divided Class II subjects into two groups with and without open bite malocclusion. It was found that the open bite subjects had discrepancies in the upper and lower skeletal basal bone that would eventually require orthognathic surgeries for their correction.

The functional etiologic origin was studied by Arat et al., $2008{ }^{12}$. In their study, the authors compared a group having anterior open bite, with different Angle's classifications, to a group having Class I relation (control group). The contribution of functional aspect was found to be one of the main etiological factors in the development of the malocclusion. This had driven us to assess the role of abnormal oral habits and to compare their ratio of occurrence between both the open bite and normal occlusion groups.

It was proven that the growing open bite subjects should be managed early during their pubertal spurt. On the other hand, the late pubertal spurt was recommended for the treatment of deep bite malocclusion ${ }^{13}$. Thus, emphasizing the importance of early analysis of the underlying cause; aiming to address it during treatment.

According to the results of a previous study, the dental components of malocclusion such as the increased labial inclination of the upper incisors and the flattened curve of Spee were proven to have a high contribution in the development of dental open bites ${ }^{14}$. The findings of the current study confirmed the contribution of such factors by having a significant difference in their mean values when compared to a control group. Accordingly, buccal segment extractions in open bite cases would help both in regaining the normal incisors torque together with reducing anterior bite depth ${ }^{15}$.

The angulation of the upper and lower first molars (mesial tipping) did not show statistical significance between the 2 groups. This clarified the diminished need for the distal tipping kim $^{16}$ mechanics in the treatment of dental open bite. Moreover, distal tipping could also lead to extrusion of molars that can open the bite more anteriorly ${ }^{17}$. 
Since dental open bites are commonly seen during the early developmental stages, therefore habit breakage is a common way for treating such a malocclusion via addressing its underlying etiologic factor. Thumb sucking, tongue thrusting and mouth breathing habits were proven to be significantly common among children having dental open bite according to the results of the present study which was in accordance with findings of $\mathrm{El}$ Dawlatly et al. ${ }^{3}$

The orthodontist would be more accurate in customizing the treatment mechanics tailored for each open bite case, putting in mind the contributing dental and environmental factors. A translation of the present results could uncover the need for early treatment of growing open bite patients. This might overcome the developing discrepancies in a growing child.

\section{CONCLUSIONS}

1) The proclination of the upper incisors together with the flat curve of Spee were significantly displayed in the open bite group.

2) Thumb sucking, tongue thrusting and mouth breathing habits were significantly more common in open bite cases when compared to the control group.

3) The treatment planning protocol of open bite should be customized according to the underlying components.

\section{REFERENCES}

1. Ng CS, Wong WK, Hagg U, 2008.Orthodontic treatment of anterior open bite. International Journal of Pediatric Dentistry; 18: 78-83.

2. Proffit WR, Fields HW, Moray LJ, 1988. Prevalence of malocclusion and orthodontic treatment need in the United State estimate from the N-HANES III survey. Int J Adult Orthod Orthognath Surg;13:97-106.

3. El Dawlatly MM, Fayed MS, Mostafa YA, 2015. Open bite malocclusion: Analysis of the underlying components., Dent Oral Craniofac Res, 2015;1(1): 19-24 .
4. Gurton AU, Akin E, Karacay S, 2004. Initial intrusion of the molars in the treatment of anterior open bite malocclusions in growing patients. Angle Orthod.,74:454-464.

5. Huang GJ, Drangsholt M, 2001. Stability of anterior open bite correction with MEAW. Am J Orthod Dentofacial Orthop.,119:14A.

6. Erverdi N, Keles A, Nanda R, 2004. The use of skeletal anchorage in open bite treatment: a cephalometric evaluation. AngleOrthod.,74:381-390.

7. Sherwood KH, Burch JG, Thompson WJ. Closing anterior open bites by intruding molars with titanium miniplate anchorage. Am J Orthod Dentofacial Orthop 2002;122:593-600.

8. Kuroda S, Sakai Y, Tamamura N, Deguchi T, TakanoYamamoto T, 2007. Treatment of severe anterior open bite with skeletal anchorage in adults: Comparison with orthognathic surgery outcomes. Am J Orthod Dentofacial Orthop,132:599-605.

9. Beane R, Reimann G, Phillips C, Tulloch C, 2003.A Cephalometric Comparison of Black Open-Bite Subjects and Black Normals. Angle Orthod,73:294-300.

10. Ellis E, McNamara JA, 1984. Components of adult Class III malocclusion. J Oral Maxillofac Surg.,42(5):295-305.

11. Ellis E, McNamara JA, Lawrence TM, 1985. Components of adult Class II malocclusion, 43(2):92-105.

12. Arat ZM, Akcam MO, Esenlik E, Arat FE, 2008. Inconsistencies in the Differential Diagnosis of Open Bite. Angle Orthodontist, 78:415-420.

13. Nanda SK, 1990. Growth patterns in subjects with long and short faces. Am J Orthod Dentofacial Orthop;98:247-58.

14. Sangcharearn Y, Christopher HO, 2007. Effect of incisors angulation on overjet and overbite in Class II camouflage treatment. Angle Orthod,77:1011-8.

15. Garlington M, Logan LR, 1990. Vertical changes in high mandibular plane cases following enucleation of second premolars. Angle Orthod., 60: 263-267.

16. Kim YH, Han UK, Lim DD, Serraon ML. Stability of anterior openbite correction with multiloop edgewise archwire therapy: a cephalometric follow-up study. Am J Orthod Dentofacial Orthop 2000;118:43-54

17. Lee HA, Park YC, 2008. Treatment and post-treatment changes following intrusion of maxillary posterior teeth with miniscrew implants for open bite correction. Korean J Orthod, 38:31-40. 